\title{
Avaliação psicológica de agressores sexuais no contexto brasileiro: instrumentos e perspectivas
}

\section{Psychological assessment of sexual offenders in the Brazilian context: instruments and perspectives}

\section{Álice Lira-Cardoso ${ }^{1}$}

Universidade Federal da Paraíba - João Pessoa/Paraíba, Brasil alicetlcardosos@gmail.com

http://lattes.cnpq.br/7678754881977497

(D) http://orcid.org/0000-0003-4648-498X

\section{Gabriella Medeiros Silva²}

Universidade Federal da Paraíba - João Pessoa/Paraíba, Brasil medeirosgabriella7@gmail.com http://lattes.cnpq.br/7976072539402047 https://orcid.org/0000-0002-5224-5865

\section{Thiago Pinto Siqueira Campos ${ }^{3}$}

Universidade Federal da Paraíba - João Pessoa/Paraíba, Brasil thiagosiqueirajp@gmail.com http://lattes.cnpq.br/9612818353542939

D https://orcid.org/0000-0002-7613-9485

\section{Lizandra Monteiro Ciraulo ${ }^{4}$}

Universidade Federal da Paraíba - João Pessoa/Paraíba, Brasil lizandraciraulo@hotmail.com http://lattes.cnpq.br/6389188444774940

https://orcid.org/0000-0002-1049-3983

1 Graduanda em Psicologia pela Universidade Federal da Paraíba.

2 Graduanda em Psicologia pela Universidade Federal da Paraíba.

3 Graduando em Psicologia pela Universidade Federal da Paraíba.

4 Graduanda em Psicologia pela Universidade Federal da Paraíba. 
Carmen Walentina Amorim Gaudêncio Bezerra ${ }^{5}$

Universidade Federal da Paraíba - João Pessoa/Paraíba, Brasil camorimg@gmail.com

http://lattes.cnpq.br/9578405957302211

https://orcid.org/0000-0001-5972-1601

Resumo: A avaliação clínica forense é um processo ético-técnico-científico que investiga os processos psicológicos (emocionais, cognitivos e comportamentais), de um ou mais indivíduos, envolvidos em um delito, visando satisfazer a uma demanda do contexto legal. Este artigo objetivou trazer à tona a situação atual da avaliação psicológica no contexto forense brasileiro, com o foco nos "agressores sexuais". Para tal, realizou-se uma revisão narrativa da literatura científica nacional por meio de artigos e capítulos de livros com atenção aos componentes metodológicos da avaliação psicológica (entrevista e testagem psicológica propriamente dita) sobre a avaliação de personalidade, do risco de violência e da reincidência criminal, da agressividade, de psicopatia e da impulsividade, variáveis implicadas nesse contexto. Além disso, observou-se o embasamento legal para a atuação do psicólogo forense nos âmbitos regidos pelo Código Penal, pelo Código Processual Penal e pela Lei de Execução Penal. Os resultados apontam para uma escassez científica e metodológica nacional, sobre a avaliação dos agressores sexuais. Entretanto, os estudos desenvolvidos estão avançando no sentido de dirimir tal lacuna, de modo que quanto mais experiência no contexto legal, mais apto estará o psicólogo forense a satisfazer as demandas jurídicas.

Palavras-chave: Avaliação Clínica Forense; Agressores Sexuais; Psicologia Jurídica.

5 Doutora em Psicologia pela Universidade Complutense de Madri. Psicóloga Perita Cível e Criminal nos contextos espanhol e brasileiro. Professora Associada ao Departamento de Psicologia da Universidade Federal da Paraíba. Coordenadora e Líder do Laboratório de Avaliação e Intervenção Clínica Forense - LAICF/UFPB/CNPq. Coordenadora do GT Criminal e Penitenciária da Associação Brasileira de Psicologia Jurídica - APBJ. Parecerista Ad Hoc do Sistema de Avaliação de Testes Psicológicos - SATEPSI/CFP. 
ABSTRACT: Forensic clinical assessment is an ethical-technical-scientific process that investigates the psychological processes (emotional, cognitive and behavioral) of one or more individuals involved in an offense, aiming to satisfy a demand of the legal context. This article aimed to bring up the current situation of psychological evaluation in the Brazilian forensic context, focusing on "sexual offenders". To this end, a narrative review of the national scientific literature was carried out through articles and book chapters, with attention to the methodological components of psychological assessment (interview and psychological testing itself) on the assessment of personality, risk of violence and violence. criminal recidivism, aggressiveness, psychopathy and impulsivity, variables involved in this context. In addition, the legal basis for the forensic psychologist's work was observed in the areas governed by the Penal Code, the Penal Procedural Code and the Law on Criminal Execution. The results point to a national scientific and methodological scarcity about the evaluation of sexual offenders. However, the studies developed are moving towards bridging this gap, so that the more experience in the legal context, the better the forensic psychologist will be able to satisfy the legal demands.

KeYwords: Clinical Forensic Assessment; Sexual Offenders; Juridical Psychology.

SUMÁRıo: Introdução; Método; 1. Avaliação Psicológica; 1.1 Entrevista; 1.2 Avaliação da Personalidade; 2. Avaliação de risco e reincidência; 3. Instrumentos para avaliação de risco em agressores sexuais; Considerações Finais; Referências.

\section{INTRODUÇÃO}

A Violência sexual é um tema que vem recebendo muita atenção nos últimos anos (SOUSA, 2017; TEIXEIRA-FILHO et al., 2013). No entanto, definir o que é considerado violência sexual não é tão simples quanto pode parecer à primeira vista (INOUE; RISTUM, 2008). $\mathrm{Na}$ literatura, não existe consenso quanto a própria definição do termo violência (RISTUM; BASTOS, 2004), visto que a conceituação ou classificação da violência depende do julgamento social e do contexto 
histórico, de modo que não segue critérios únicos, dando margem para uma pluralidade de definições (EMERY; LAUMANN-BILLINGS, 1998). A Legislação vigente considera que - Art. 213 do Código Penal e Lei 12.015/09 - a violência sexual, como o estupro, envolve o ato de “constranger alguém, mediante violência ou grave ameaça, a ter conjunção carnal ou a praticar ou permitir que com ele se pratique outro ato libidinoso" (BRASIL, 1940; 2009, n.p.).

Em se tratando de crimes de agressão sexual, dados do Fórum de Segurança Nacional em seu Anuário Brasileiro de Segurança Pública trazem que, durante o ano de 2018, os registros de violência sexual atingiram a marca de 66,041 mil casos no Brasil. Destes, as mulheres representaram $81,8 \%$ das vítimas, sendo que mais da metade deste número se refere a meninas de até 13 anos de idade (FBSP, 2019). Estes dados refletem o aumento dos crimes sexuais no território brasileiro, levando à preocupação em investigar acerca dos indivíduos que cometem estes atos.

No decorrer de uma investigação criminal pode surgir a necessidade de averiguar outros aspectos do acusado como sua saúde física e mental (HUSS, 2011). Esse tipo de elucidação é chamado de perícia no âmbito do Processo Penal e é considerada um meio de prova (CAPEZ, 2019). O exame pericial, como colocado por Netto (2014), serve para elucidar fatos que fogem ao conhecimento geral, uma vez que o profissional responsável por realizá-lo deve ser alguém com formação técnica científica na área em específico (CAPEZ, 2019).

O processo de avaliação psicológica forense, nesse sentido, é um tipo de perícia que geralmente consiste na realização de uma entrevista, aliada (ou não) à aplicação de testagem psicológica - objetiva, projetiva ou de ambos os tipos, com o propósito de examinar a situação biopsicossocial do sujeito em atenção à demanda da Justiça (SANTOS; ANDRETTA; COUTO, 2012). Um exemplo seria a perícia para avaliar questões de inimputabilidade e periculosidade, ambas dependentes do estado mental do sujeito (CAPEZ, 2019). Para Hüss (2011) a avaliação psicológica forense foca em coletar informações diversas para concluir sobre a dinâmica do funcionamento psicológico de um indivíduo, em dado momento.

Em países como Estados Unidos (EUA), Reino Unido, Espanha e Portugal são utilizados habitualmente uma variedade de métodos 
validados na avaliação clínica forense. A especificidade dos instrumentos utilizados na avaliação dos indivíduos - em conflito com a lei - é de suma importância pois informa sobre temas que ultrapassam o conhecimento do Direito. Há diversos instrumentos construídos e utilizados para atender às demandas específicas da Justiça, chamados de instrumentos forenses especializados, os quais atendem a um padrão legal (HÜSS, 2011; HERMOSO, 2019). No Brasil, por outro lado, a avaliação clínica forense ainda é pouco desenvolvida, quando comparada aos países supracitados. A saber, considerando a avaliação de indivíduos que cometem crimes de agressão sexual, os instrumentos utilizados não diferem dos instrumentos tradicionais, a exemplo dos testes de personalidade como o de Rorschach (FERES, et al., 2002). Isso é um ponto importante que está diretamente relacionado com o escasso desenvolvimento na área.

Nesse sentido, estudos brasileiros voltados à avaliação de populações de instituições penais, quando realizados, envolvem poucos instrumentos ou métodos avaliativos, sendo poucos os casos nos quais a avaliação de risco de violência é realizada. Considerando a mudança de regime de pena, essa avaliação tem sido feita meramente com a observação do bom comportamento do apenado, aspecto que pode ser manipulado com facilidade por interesses individuais (FERES et al., 2002; WRUBEL, 2013). Ainda, por vezes os responsáveis pela avaliação do bom comportamento do sentenciado são o agente chefe da segurança e principalmente o diretor do presídio, independentemente do crime cometido. Esse é um fato que dista muito do que ocorre no contexto internacional e ainda que esteja prevista em lei a individualização da pena e o acompanhamento global do preso, as carências nesse sentido são alarmantes (KARAM, 2011).

Promove-se a importância dos dados acima apresentados, principalmente, na tentativa de demonstrar que a avaliação psicológica forense não deve ser restrita ao acusado ou ao apenado. Deve-se primar pelos métodos e técnicas desse procedimento técnico-ético-científico também enquanto há suspeitos, investigados, indiciados, acusados. Isso corrobora a ideia da utilização de todos os meios de prova (neste caso, seja documental ou pericial; BRASIL, 1941) para aumentar a confiabilidade da apuração dos fatos. Por fim, salienta-se que a avaliação psicológica forense não visa atingir uma "verdade real", ou quaisquer de suas variantes, a exemplo da correspondente (KHALED JR., 2015), mas fornecer 
elementos probabilísticos/científicos para que os operadores do Direito possam minimizar o erro na persecução penal.

Nesse sentido, o artigo em questão é uma revisão narrativa sobre os processos de avaliação psicológica de agressores sexuais no contexto brasileiro, com o objetivo de verificar quais métodos e instrumentos podem ser utilizados na avaliação da personalidade, assim como nas avaliações de risco de violência e reincidência criminal dessa população, identificando avanços e deficiências nesse contexto. Finalmente, analisar a possibilidade de atuação do psicólogo forense frente às demandas da Justiça, considerando que a avaliação psicológica é função privativa do psicólogo - Lei no 4.119/CFE (BRASIL, 1962) e de fundamental importância para assessorar na tomada de decisões judiciais - estabelecimento/ manutenção da sentença e tratamento penal (HÜSS, 2011).

\section{MÉTOdo}

O presente estudo trata-se de uma revisão narrativa da literatura brasileira acerca do processo de avaliação psicológica forense de agressores sexuais. Segundo Rother (2007), a revisão narrativa permite conhecer um determinado tema de forma ampla e em curto espaço de tempo, pois não exige um protocolo rígido de análise dos resultados encontrados nas buscas realizadas e as informações são escolhidas de acordo com sua relevância.

O processo de coleta do material ocorreu de forma não sistemática no período de agosto a novembro de 2019. Foram realizadas buscas na base de dados Scielo, complementadas pela ferramenta de pesquisa de materiais acadêmicos Google Scholar. Além disso, também foram incorporados os materiais indicados por especialistas na área.

\section{Avaliação Psicológica}

No Brasil, ao revisar as fontes bibliográficas, identifica-se que a avaliação psicológica de agressores sexuais pode ser realizada durante uma perícia forense ou, a depender da demanda judicial, numa consultoria forense por meio do profissional psicólogo. Esse processo 
ético-técnico-científico tem como finalidade auxiliar a justiça na tomada de decisões judiciais. Para isso, o psicólogo avaliador deve utilizar métodos reconhecidos cientificamente, abordando as margens de erro probabilísticas, tendo em vista que não se chega, a partir desses processos, a uma verdade absoluta, a exemplo dos casos de reincidência de crimes sexuais (FONSECA, 2006).

Objetiva-se, com a avaliação psicológica forense, averiguar as condições psicológicas (afetivas/emocionais, cognitivas e comportamentais) dos sujeitos relacionados a um crime em questão (sejam eles as vítimas, testemunhas ou agressores) para subsidiar as decisões correspondentes ao seu encarceramento ou não, e ainda determinar que tipo de tratamento penal seria o mais apropriado para cada caso (HÜSS, 2011). Investigam-se aspectos como a presença de transtornos mentais (que comprometam a capacidade de entendimento e autodeterminação); motivações internas e externas; fatores contextuais (ambientais, culturais etc.), entre outras variáveis que possam ter auxiliado na ação/omissão delituosa (ROVINSKI, 2013).

Dentre as formas para a investigação supracitada, diversas técnicas podem ser utilizadas, tais como entrevistas, observação lúdica, aplicação de testes (neuropsicológicos e de personalidade), observação clínica e análise de documentos referentes ao caso (SERAFIM; SAFFI, 2014). Assim, após a conclusão da avaliação psicológica, o psicólogo deve elaborar um laudo, seguindo as diretrizes da Resolução $n^{\circ}$ 06/2019 do Conselho Federal de Psicologia (CFP, 2019). Esse laudo é encaminhado para a autoridade querelante da avaliação e deve conter a descrição da forma como o examinando percebe suas relações e o ambiente que o rodeia, bem como possíveis déficits cognitivos, características de personalidade e/ ou transtornos psiquiátricos ou psicológicos. Os dados da história devem ser correlacionados com o funcionamento atual do indivíduo avaliado, objetivando comparar a queixa com as características apresentadas na avaliação (SERAFIM; SAFFI, 2014).

Durante a avaliação, Silva (2013) alerta sobre o cuidado que o perito deve ter com o falso testemunho no momento de entrevistar e coletar dados junto às crianças potenciais vítimas de abuso sexual e seus familiares. Fatores como transtornos psicológicos (do cuidador ou da criança), alienação parental por motivo de guarda, ou consumo de 
substâncias químicas, por exemplo, podem interferir na veracidade do depoimento. Até mesmo a postura do psicólogo na condução da entrevista poderia influenciar nas respostas obtidas, visto que a gravidade do crime pode desafiar os princípios e a imparcialidade do profissional com relação à presunção de inocência do acusado (SILVA, 2013).

O CFP, em sua Resolução $n^{\circ}$ 017/2012, trata sobre a atuação do psicólogo como perito nos diferentes contextos. No art. $8^{\circ}$, é apontado que cabe ao parecer do psicólogo perito indicativos relevantes ao objetivo da avaliação. Essa relevância deve ser direcionada à demanda atendida, auxiliando as decisões da Administração Pública, respeitando os limites da atuação do profissional da Psicologia (CFP, 2012). Ou seja, o trabalho do perito, nesse caso, é apresentar informações ao juiz (ou a outro requerente) a partir do ponto de vista teórico-científico psicológico, amparando o que lhe foi solicitado.

Ademais, o laudo psicológico, como meio de devolutiva dos resultados da avaliação psicológica, é denominado documento psicológico, definido pelo Art. $4^{\circ}$ da Resolução CFP 06/2019 como um "instrumento de comunicação escrita resultante de serviço psicológico à pessoa, grupo ou instituição” (CFP, 2019). No Código de Processo Penal, Art. 232, documentos são considerados "quaisquer escritos, instrumentos ou papéis, públicos ou particulares” (BRASIL, 1941). Dito isso, ao investigar sobre o conceito de prova no Direito, Aragoneses Alonso (1984, p. 278, apud LOPES JR., 2019, p. 503) explana que "toda classe de objetos que tenham uma função probatória, contanto que esses, por sua índole, sejam suscetíveis de ser levados ante a presença judicial”, podem ser caracterizados como prova documental.

Os documentos podem ser apresentados no processo a qualquer tempo, como definido no art. 231 do CPP (BRASIL, 1941), desde que não sejam casos já definidos por lei. Havendo dúvidas sobre a integridade mental no curso do processo, o juiz poderá ordenar que seja realizado um exame médico-legal do acusado (CPP, art. 149; BRASIL, 1941). Dito isso, é importante referir que o CPP não estabelece um momento apropriado sobre quando as provas periciais devem ser produzidas durante a instrução processual, à parte das concebidas no primeiro momento do inquérito policial (SALMEIRÃO, 2012), que é uma das possibilidades estabelecidas no $\S 1^{\circ}$, art. 149 do CPP, anteriormente mencionado. 
Salienta-se, ainda, que todo esse processo é embasado legalmente, tendo em vista leis como: Lei ${ }^{0} 7.210$ de Execuções Penais, de 11 de julho de 1984 , cujo art. $5^{\circ}$ que cita a personalidade do condenado como modo classificatório para orientação da individualização da pena; art. $9^{\circ}$ coloca entrevistas, diligências e exames para aspectos da personalidade e art. 180 discorre sobre a conversão de pena utilizando dados personalísticos (BRASIL, 1984); Código Penal - Decreto-Lei nº 2.884/1940, em que os art. 59, art. 67, art. 71 parágrafo único e art. 77 inciso II discorrem sobre aspectos aos quais o juiz deve atentar, sendo eles a "conduta social, à personalidade do agente, aos motivos e consequências do crime, bem como ao comportamento da vítima" (BRASIL, 1940); Código Processual Penal - Decreto-Lei n ${ }^{\circ} 3.689 / 1941$ onde artigos 149 a 154 fazem parte de um capítulo intitulado "Da Insanidade Mental do Acusado"; entre outros artigos dessa Lei (BRASIL, 1940).

Cabe esclarecer, por fim, que o "exame criminológico" é uma avaliação psicológica feita no apenado que objetiva descrever como o tratamento penal influencia na sua subjetividade para predizer a sua suposta reinserção na sociedade (REISHOFFER; BICALHO, 2017). É embasada pela súmula vinculante $n^{\circ} 26$ do STF e pela súmula 439 do STJ, entretanto, somente é feita a depender de particularidades do caso (crimes hediondos ou equiparados) e da decisão fundamentada para tal exame (BRASIL, 2009; 2010). Assim, por mais que, semelhantemente à avaliação psicológica forense, haja uma investigação acerca da conduta do apenado, considerando sua relação familiar e social, precedentes pessoais, fatores bio-psíquico-sociais etc. (PENIDO; GONÇALVES, 2015), esse exame ocorre somente na última fase do processo de persecução penal.

Por mais que muitas decisões sobre a progressão de pena desses indivíduos sejam feitas baseadas no exame criminológico, entende-se que limitar a avaliação psicológica forense a essa etapa é insuficiente. Compreende-se que a execução dessa avaliação noutros momentos da persecução penal traria maior conhecimento para embasar as decisões judiciais. Entretanto, o artigo 112 da Lei 10.792 de 2003 (Lei de Execuções Penais) alterou significativamente a necessidade do exame criminológico para a progressão de regime por um simples atestado de bom comportamento carcerário, ficando a critério do magistrado requerer o 
referido exame. Ainda que, no caso do livramento condicional o exame deva ser realizado, já que o artigo 83 do Código Penal e o artigo 131 da Lei de execução penal não sofreram alterações.

\subsection{ENTREVISTA}

A entrevista psicológica pode ser definida como a coleta de informações sobre um indivíduo, considerando-o como fonte complementar juntamente àqueles relacionados de forma significativa ao caso em questão. No âmbito legal, ela comumente engloba diversos aspectos da vida como família, trabalho, saúde mental, abuso de substância, educação ou envolvimento legal (JUNG, 2014). É considerada, de forma geral, uma das partes mais importantes durante o processo de avaliação psicológica, pois fornece um norte que servirá de base para o psicólogo conduzir as demais fases. Além disso, auxilia no estabelecimento do rapport, facilitando a honestidade e a confiança do examinando frente ao psicólogo (FRAGA, 2016).

Outros aspectos facilitados pela entrevista clínica forense se referem ao enquadramento e a observação do examinando. Além das perguntas realizadas a fim de conhecer a história de vida, familiar e criminológica, durante o ato da entrevista, especificamente no caso da entrevista inicial, o psicólogo irá apresentar a si próprio, bem como explicará o processo avaliativo, em que consistirá e com qual objetivo (ALMEIDA, 2004). Se o examinando tiver dúvidas acerca do processo, esse também é o momento ideal para esclarecê-las. Ademais, ao longo da entrevista, o psicólogo deve estar atento à linguagem verbal e não-verbal do avaliando, suas reações e se há contradições na fala (JUNG, 2014).

No tocante à avaliação de agressores sexuais, durante as buscas para a revisão, não foi encontrado nenhum modelo de entrevista específico para ser utilizado com esse público no contexto brasileiro. No entanto, Jozef e Silva (2002) desenvolveram um modelo de entrevista semiestruturada adaptado à realidade psiquiátrico-forense do Brasil, que pode ser utilizado para populações violentas específicas, incluindo estupradores e outros criminosos sexuais. Trata-se de um instrumento prático, pensado para ser empregado em delegacias, presídios e outras 
instituições forenses, onde as circunstâncias inviabilizam uma avaliação extensa (JOZEF; SILVA, 2002).

Tal modelo é composto por onze partes. As duas primeiras estão relacionadas aos aspectos de identificação do examinando, o terceiro ponto refere-se às queixas atuais (tanto a principal como as secundárias), o quarto diz respeito à história da doença atual, o quinto corresponde à história pessoal e o sexto refere-se à história familiar (deve ser colhida quando possível também com os familiares). Essas partes compreendem a anamnese, semiestruturada, permitindo a livre expressão de quem está sendo avaliado. O sétimo e oitavo pontos dizem respeito à análise do estado do examinando, psíquico e físico, respectivamente. Há uma lista de sintomas que deve ser respondida, em sua maioria com "sim" ou "não", tornando essa parte bastante prática. O nono ponto compreende os exames laboratoriais, que são solicitados apenas quando necessários ao diagnóstico. A décima parte se refere à aplicação de instrumentos complementares, como escalas de psicopatia ou outros exames. E, por se tratar de um modelo desenvolvido por psiquiatras, o último ponto é o diagnóstico - CID-10 (JOZEF; SILVA, 2002). Embora esse modelo seja desenvolvido por psiquiatras pode ser utilizado por psicólogos durante a avaliação psicológica forense. E, ainda que o foco da avaliação não seja unicamente realizar um diagnóstico clínico ou de personalidade, este pode vir a ocorrer quando o avaliado expressar características condizentes com alguma psicopatologia, principalmente se essa informação for relevante para o caso analisado judicialmente - solicitada ou não pelo querelante (MESSA, 2010).

No Brasil, a literatura acerca da avaliação psicológica forense de agressores sexuais é escassa e os estudos encontrados focam em criminosos ligados ao abuso sexual infantil como o de Reis (2016), sendo a entrevista uma das técnicas mais utilizadas. Dentre os artigos encontrados, cita-se o de Zúquete e Noronha (2012), que avaliaram 108 réus de crimes sexuais contra crianças e adolescentes em Salvador BA. Para tal, desenvolveram um roteiro de entrevista próprio para a pesquisa, baseado na bibliografia específica sobre o tema. Os autores encontraram na fala dos entrevistados negação do crime, culpabilização de suas ações pelo uso do álcool e/ou outras drogas ilícitas, violência física no ambiente carcerário contra os presos por crimes sexuais, o 
que os leva a esconder o motivo da sentença por medo de retaliações dos outros presos (ZÚQUETE; NORONHA, 2012).

Outros aspectos de interesse de estudos nacionais com agressores sexuais mediante entrevistas semiestruturadas como instrumento de pesquisa, envolvem: empatia (MOURA; KOLLER, 2010), visão de acusados de abuso sexual sobre como deve ser o relacionamento ideal entre crianças e adultos (MOURA; KOLLER, 2008), personalidade e transtornos psiquiátricos (RIGONATTI et al, 2006). Nos estudos de Moura e Koller $(2008,2010)$ os agressores sexuais apresentaram uma visão estereotipada e politicamente correta acerca de como deve ser o relacionamento entre adultos e crianças. Para os entrevistados, de modo geral, essa relação deveria ser de cuidado dos adultos para com as crianças e respeito mútuo. Além disso, os participantes demonstraram possuir habilidade empática geral. Isso fez com que fosse levantado o questionamento sobre se haveria realmente um déficit empático de forma geral em agressores sexuais ou apenas em relação à vítima ou grupos específicos (PITHERS, 1999; WEBSTER; BEECH, 2000).

Além desses estudos que englobavam a avaliação de mais de um indivíduo, Pimentel (2010) realizou dez entrevistas individuais com um apenado no Pará. O autor incluiu no protocolo outros métodos avaliativos como a observação sistemática, o Rorschach e relatos escritos do participante. A análise do discurso em conjunto com a interpretação das respostas do Rorschach revelou violência sexual intrafamiliar sofrida na infância; estrutura e dinâmica de personalidade frágil; agressividade e um perfil de pedofilia (PIMENTEL, 2010).

Os exemplos citados demonstram que a entrevista é um dos principais recursos utilizados no processo de avaliação psicológica. Contudo, observa-se uma heterogeneidade no formato dessas entrevistas com agressores sexuais, dado que são elaboradas conforme os objetivos de pesquisa. Além disso, nenhum dos estudos analisados apresentou resultados sobre o contexto de avaliação clínica forense. No entanto, esses fatores não impedem que algum dos modelos (de forma integral ou adaptada) possa guiar a condução de uma entrevista fora do âmbito da pesquisa, tendo em vista que o formato da entrevista é determinado pelo objetivo da avaliação e que o psicólogo responsável por sua condução pode (e deve) se embasar na literatura da área para a construção do roteiro. 


\subsection{Avaliação da Personalidade}

Segundo Pervin e John (2004), a personalidade pode ser entendida como as características do indivíduo que evidenciam padrões constantes de comportamentos, sentimentos e pensamentos. Neste sentido, embora não exista um único perfil de agressores sexuais, a análise e a investigação de traços e sinais que possam estar relacionados a esse tipo de conduta é de extrema importância, fazendo-se necessária para que possa facilitar a identificação desses indivíduos e a compreensão do que os leva a agirem dessa forma (CASARIN; BOTELHO; RIBEIRO, 2016).

Para a realização desse tipo de avaliação é imprescindível que se combine instrumentos de naturezas distintas, de forma a captar o máximo de informações possíveis acerca do avaliando (HISATUGO; CUSTÓDIO, 2013; NORONHA, 2002). Os testes objetivos possibilitam uma compreensão mais rápida e geral do fenômeno em estudo, porém têm como limitações o possível mascaramento de informações pelo avaliando (FORMIGA; MELLO, 2000). Na avaliação da personalidade de agressores sexuais, os instrumentos objetivos, frequentemente utilizados a nível mundial são o MMPI-2 (Minnesota Multiphasic Personality Inventory) e o MCMI - III (Millon Clinical Multiaxial Inventory), mais especificamente para abusadores de crianças (PECHORRO; POIARES; VIEIRA, 2008). Cabe informar que as versões dessas provas trazem escalas de validade que permitem identificar vários fatores de viés interpretativo como a mentira, a dissimulação de sintomas, a desejabilidade social etc., além de perfilar um código que possibilita a integração dos principais resultados.

Os testes (ou técnicas) projetivas, por outro lado, permitem acessar diversos âmbitos da psique de quem está sendo avaliado, sendo mais difícil enganar os resultados de acordo com a imagem que deseja passar. Contudo, um lado negativo dessa perspectiva mais subjetiva é o viés de interpretação do avaliador (FORMIGA; MELLO, 2000). No Brasil, ainda que a prática da avaliação da personalidade de presos não seja comum, quando realizada é apenas por meio do uso de testes projetivos como o método de Rorschach e o HTP (House, Tree, Person; FERES et al., 2002; SCORTEGAGNA; AMPARO, 2013).

O Rorschach é um instrumento que permite investigar as disposições da personalidade. O teste é composto por 10 lâminas representadas 
por manchas de tinta simétricas e diferentes entre si (SCORTEGAGNA; AMPARO, 2013), sendo um dos métodos mais aceitos pelos profissionais de Psicologia (NASCIMENTO, 2002). O método de Rorschach foi utilizado em um estudo realizado com detentos ofensores sexuais de uma penitenciária no Rio Grande do Sul para avaliar as características da personalidade voltadas à autopercepção, ao relacionamento e à percepção interpessoal, ao ajustamento perceptivo, à pressão interna e ao autocontrole (SCORTEGAGNA; AMPARO, 2013).

As configurações dos borrões são ambíguas, mas cada uma das lâminas apresenta uma proposital simetria e harmonia perceptiva que, segundo pesquisas, representam os estímulos que existem em nossa realidade. Além da presença ou não de cores, os estímulos podem ser organizados considerando uma maior participação da forma, percepção de espaço, perspectiva, integração entre figura e fundo, luminosidade, movimento (MORANA, 2003). A interpretação do Rorschach é complexa e exige um longo treinamento para sua eficácia. Além de que, o teste tem vários métodos ou linguagem de interpretação o que dificulta ainda mais o processo e replicação de estudos. Portanto, caso esse critério não seja devidamente atendido a possibilidade de sesgos é aumentada, prejudicando sobremaneira a confiabilidade da avaliação.

De acordo com Scortegagna e Amparo (2013), os principais resultados no estudo com detentos ofensores sexuais indicaram baixa autoestima, danos na autoimagem, distanciamento nas relações pessoais e dificuldades de empatizar com outros, conflitos de identidade, incapacidade de abstração de papéis e funções sociais e mediação cognitiva afetada, resultando em uma interpretação equivocada da realidade. Esses dados destacam um grave comprometimento nas organizações psicológicas desses indivíduos.

A técnica projetiva de desenho HTP é utilizada para obter informações acerca da experiência individual em relação aos outros e ao ambiente. O avaliando expressa, em um papel, áreas de conflito e elementos da sua personalidade. A técnica se realiza em algumas etapas. A primeira consiste na execução do desenho acromático de uma casa, uma árvore e uma pessoa. Após os desenhos, o psicólogo deve fazer um inquérito estruturado acerca das associações do indivíduo com cada desenho. A terceira e quarta etapas são semelhantes às primeiras, só que os 
desenhos são feitos com giz de cor. A análise dos desenhos baseia-se no conteúdo, levando em consideração tamanho, localização, ausência ou não de algumas partes e respostas dadas no inquérito (BUCK, 2003). Desse modo, o significado da informação não se fundamenta na comparação dos resultados do indivíduo com grupos previamente estabelecidos, mas com sua própria performance (BORSA, 2010).

Em um estudo realizado por Feres et al. (2002), com o propósito de identificar características psicológicas que pudessem estar relacionadas a algum transtorno mental, em um grupo de 257 presos do Instituto Penal Agrícola Dr. Javert de Andrade, no estado de São Paulo, demonstrou-se que, ao serem categorizados de acordo com o crime cometido, os estupradores constituíram a categoria que mais se diferenciou do restante; isto é, exibiram conduta discrepante em questões como o alto nível de agressividade, periculosidade e impulsividade. Os dados obtidos revelaram que, no grupo de estupradores, havia um contingente extremamente alto de indivíduos que apresentavam personalidades psicopáticas, análise alcançada por meio da aplicação do teste projetivo Casa-Árvore-Pessoa (House, Tree, Person - HTP; FERES et al., 2002).

Em estudo realizado por Gonçalves et al. (2016), com o objetivo de investigar as características psicológicas dos acusados de abuso sexual infantil, utilizou-se o teste projetivo HTP no estado do Mato Grosso do Sul. Por meio da análise dos desenhos realizados pelos agressores, observou-se que esses indivíduos apresentaram dificuldades em caracterizar a sexualidade do desenho da pessoa. Isso retrata uma aversão ao corpo e ao universo adulto. Também exibiram níveis de infantilidade, insegurança e fantasia, além da frequente presença de conflitos sexuais, hostilidade, fixação em algum momento do passado, entre outros (GONÇALVES et al., 2016).

Em estudo semelhante, Casarin et al. (2016) fizeram a utilização do Desenho da Figura Humana (DFH) para avaliar a presença de dificuldades em lidar com comportamentos impulsivos em prol da satisfação imediata de necessidades, verificada através de características dos desenhos das figuras humanas. O DFH é um instrumento projetivo que propõe avaliar a capacidade cognitiva e aspectos da personalidade, sendo uma forma de medida não-verbal, de fácil aplicação e baixo custo, tendo sido validado para o Brasil, em 2003, por Wechsler. Neste sentido, o DFH está baseado na premissa de que ao realizar o desenho, o indivíduo 
está colocando no papel como se enxerga e como acredita que as pessoas o enxergam (SILVA et al., 2010). A partir do desenho, são avaliados 30 itens, se estão presentes ou ausentes, que, somados, levam a um score global, no qual 0 significa que não apresenta distúrbios emocionais, 1 indica que não há sinais de problemas emocionais e 2 ou mais indica a presença de distúrbios (AZEVÊDO, 2010).

Os participantes desse estudo foram 10 homens, reclusos em uma instituição penal por estupro intrafamiliar. Na linha de análise dos dados utilizada por Casarin et al. (2016) foram focalizados detalhes como a proporção do desenho, perspectiva e os detalhamentos, que expressam o nível de funcionamento dos indivíduos submetidos a este método (SILVA et al., 2010). Foram identificadas, nos ofensores sexuais, características de personalidade associadas à dificuldade em controlar seus impulsos corporais, mais especificamente de ordem sexual, levando à procura repentina por satisfação e, consequentemente, à possível agressão.

Os resultados obtidos pelo estudo de Casarin et al. (2016) corroboraram com resultados de outras pesquisas nacionais, apesar de somente com base neles não ser possível afirmar se as características acentuadas nos desenhos (perspectiva em relação à localização na página, tronco omitido e ausência de pupila nos olhos) se aplicam apenas ao público de agressores sexuais, ainda que indiquem dificuldades em controlar impulsos físicos e da satisfação imediata de necessidades. Nesse sentido, deve-se ter cautela com a utilização de testes projetos gráficos como o HTP e o DFH na avaliação de agressores sexuais, já que a literatura internacional não apresenta dados que recomendem tal utilização. Essa prática, portanto, pode ser considerada obsoleta e de validade questionada de acordo com as pesquisas atuais em contextos internacionais com esse tipo de população. Como já citado anteriormente, importantes inventários para a avaliação da personalidade, de validade demonstrada como o MMPI-II (Inventário Multifásico Minnesota de Personalidade - 2; FIGUEIREDO; FENSTERSEIFER, 2016) ou MCMI-III (Millon Clinical Multiaxial Inventory-III; SOUSA; ROCHA; ALCHIERI, 2011) não são usados porque não foram publicados para uso comercial, ainda que já disponham de validações. Além de utilização de protocolos e instrumentos específicos para a avaliação forense.

Assim, entende-se que apesar dos testes supracitados serem utilizados em contexto de avaliação da personalidade, eles deixam dúvidas em 
relação ao quão adequados são para essa finalidade. É recomendado que, ao realizar uma avaliação psicológica forense, caso opte pela utilização de algum teste de personalidade, seja feita uma confrontação entre os dados obtidos por diversos meios: testes projetivos; testes objetivos; entrevista e protocolos específicos. Isso garante maior validade às informações a serem documentadas. Enfatiza-se, também, a importância do instrumento (caso algum seja selecionado) ser adequado para mensurar aquilo que se deseja verificar e, se os resultados são relevantes para a demanda (judicial neste caso). Por fim, cabe salientar que os dados trazidos sobre os instrumentos citados não se referem ao uso por profissionais psicólogos forenses, mas por pesquisadores dessa área específica no contexto nacional. Portanto, é necessário incentivar a pesquisa na área da avaliação psicológica com foco na construção ou adaptação de instrumentos destinados à avaliação de agressores sexuais.

\section{Avaliação de Risco e Reincidência}

A avaliação de risco de reincidência trata-se de um processo onde são observadas as possibilidades de um sujeito voltar a cometer uma infração, utilizando-se da identificação e contabilização de fatores de risco e fatores protetivos que foram anteriormente identificados em pesquisas científicas (NEVES, 2014). Esses fatores são organizados em alguma forma consideravelmente estruturada (e.g. entrevista, instrumento) e aplicados à história do sujeito, de modo a observar quais deles estão presentes em seu contexto.

No contexto da agressão sexual, a área da avaliação de risco no Brasil parece estar em seus primeiros passos de sistematização, reunindo poucos estudos, em sua maioria teóricos, que compilam informações mais gerais acerca do tema e algumas características que podem ser identificadas na avaliação de risco de acordo com a literatura. Como aponta Wielewicki (2017), ainda não existem, no contexto brasileiro, muitos caminhos sistemáticos para a avaliação clínica forense desse tipo de agressor. Em âmbito internacional, os métodos diferem dos utilizados no Brasil, com o uso de pletismógrafo penil, instrumento que avalia mudanças na circunferência do pênis diante de estímulo visual, e castração química. 
Dentre os estudos teóricos, Dias e Rocha (2016) listam alguns aspectos que devem ser levados em consideração na avaliação de risco de agressores sexuais, sendo eles: questões sociodemográficas, histórico criminal, clínico e de desenvolvimento, e aspectos de inadaptação psicológica que podem aumentar a chance de reincidência. Contudo, esses critérios foram baseados apenas em literatura internacional e/ou pesquisas que abordam a avaliação de risco de violência de maneira mais abrangente (DIAS; ROCHA, 2016).

Em contrapartida, Marin e Baltieri (2013) apontam para uma série de fatores de risco para reincidência de agressão sexual que são próprios do contexto brasileiro, sendo eles: o consumo excessivo de álcool, a impulsividade e um histórico de abuso sexual, além de um diagnóstico de transtorno pedofílico no caso específico dos molestadores de menores. Além disso, esses autores trazem uma tradução em português (de Portugal) do SVR-20 (Sexual Violence Risk-20), um dos instrumentos mundialmente utilizados e de maior confiabilidade para predizer o risco de violência. Contudo, como no caso anterior, trata-se de uma discussão mais teórica e a versão portuguesa do SVR-20 apresentada não foi, de fato, validada para o Brasil (MARIN; BALTIERI, 2013).

Por outro lado, apesar de ainda não tratar de recursos que podem ser utilizados na avaliação de risco, Habigzang et al. (2005) apresentam alguns fatores de risco que foram observados de maneira mais sistemática na realidade brasileira: através da análise (focada na dinâmica familiar) de 71 processos acerca do abuso sexual infantil entre 1992 e 1998 , os autores apontam que questões como desemprego e dificuldades econômicas, presença de outras formas de violência, e abuso de álcool e drogas são fatores de risco associados a esse tipo de agressão sexual (HABIGZANG et al., 2005).

Em relação aos estudos que tratam especificamente da avaliação de risco em agressores sexuais, os resultados são ainda mais escassos: Meneses et al. (2016), por exemplo, indicam o uso do SVR-20 para a avaliação dos participantes de suas intervenções com adultos autores de violência sexual intrafamiliar. Contudo, não só os resultados obtidos com esse instrumento não são debatidos, como também não é mencionado por qual processo de adaptação esse instrumento passou antes de ser utilizado no contexto brasileiro. A única informação que pode ser inferida através 
das referências citadas para o SVR-20, é que a versão utilizada nesta pesquisa foi baseada na adaptação para o espanhol (MENESES et al., 2016).

Assim, é possível observar que a área de avaliação de risco de violência e reincidência criminal no contexto brasileiro conta com inúmeras limitações. As principais limitações envolvem o fato de que a maioria das publicações aborda apenas um tipo específico de agressão sexual (realizada contra crianças e adolescentes), levando à ausência de evidências sobre a eficácia de determinados métodos de avaliação e à falta de instrumentos de avaliação específicos e validados para esse contexto.

\section{INSTRUMENTOS PARA AVALIAÇÃO DE RISCO EM AGRESSORES SEXUAIS}

Em termos da busca por instrumentos utilizados para avaliação de risco em agressores sexuais, o resultado se mostrou igualmente escasso no cenário das pesquisas brasileiras, principalmente ao focar em instrumentos adaptados e validados para este país. Abaixo serão mencionados aqueles encontrados na literatura voltados à avaliação de agressores, dentre os quais nem todos são restritos necessariamente à avaliação de risco, mas têm destaque pertinente. É importante ressaltar que os instrumentos EATA (Escala para Avaliação de Tendência de Agressividade) e PCL-R (Psycopathy Checklist Revised) apresentam parecer favorável no Sistema de Avaliação dos Testes Psicológicos (SATEPSI), que é um sistema desenvolvido pelo CFP, onde uma comissão selecionada avalia a qualidade técnico-científica dos instrumentos submetidos à análise, considerando favorável ou desfavorável para uso profissional (CFP, 2018).

A Escala para Avaliação de Tendência à Agressividade está relacionada a condutas agressivas e cada um dos itens informa sobre a tendência de uma pessoa manifestar agressividade. Constituída por 40 itens com escala likert de 3 pontos, fornecendo 4 medidas. Uma das medidas está relacionada aos comportamentos mais comuns do sexo masculino, outra medida aos comportamentos mais comuns do sexo feminino, outra aos comportamentos comuns aos dois sexos e, por fim, uma medida geral de tendências à agressividade. A escala pode ser aplicada individual ou coletivamente e o tempo de resposta é de 15 minutos, aproximadamente (SISTO et al., 2008; BUSTAMANTE et al., 2016). 
Sisto, Cecilio-Fernandes e Silveira (2012) realizaram um estudo para averiguar se os itens da EATA se comportariam de forma distinta em um grupo de pessoas infratoras e um grupo de pessoas que nunca haviam cometido crime. Os resultados encontrados pelo estudo, após a análise de semelhanças e diferenças entre os comportamentos que ambos os grupos poderiam apresentar, indicaram que os comportamentos agressivos expressos apenas pelos infratores foram o de intimidação física, intimidação e vingança. Enquanto que para o outro grupo, o comportamento exclusivo foi o de irritar as pessoas.

Já o PCL-R (Psychopathy Checklist Revised) é uma escala de pontuação para avaliação de psicopatia em populações forenses masculinas desenvolvidas por Robert Hare. A escala é uma entrevista semi-estruturada na qual um indivíduo pontua ao longo de 20 itens. Para a quantificação de cada item é utilizada uma escala de 3 pontos $(0,1,2)$ que varia de acordo com a extensão verificada no sujeito. $\mathrm{O}$ escore total varia de $0 \mathrm{a}$ 40 , no entanto, 15 a 20\% dos criminosos têm um escore de pelo menos 25. Este ponto de corte pode sofrer alterações culturais (HARE, 1998 apud MORANA, 2003).

Dentre os fatores estruturais que o PCL-R possui, o fator 1 é definido pelas características nucleares dos traços de personalidade que compõem o perfil psicopata, como superficialidade, falsidade, insensibilidade/crueldade, ausência de afeto, culpa, remorso e empatia. O fator 2 é definido por comportamentos associados à instabilidade crônica, à impulsividade e ao estilo de vida antissocial (HARE, 1991 apud MORANA, 2003). Com relação à esta escala, foi encontrada uma tese de doutorado de Morana (2003) sobre a validação da mesma para o Brasil, através da identificação do ponto de corte da escala PCL-R em população forense brasileira, com auxílio do teste de Rorschach.

Para o entendimento da validação é necessário explicar dois pontos: transtorno global de personalidade (TG) e transtorno parcial de personalidade (TP), nomenclaturas de Mendes Filho (1995 apud MORANA, 2003). Para este autor, no TP, as alterações apresentadas são menos graves, permitindo uma maior integração ao meio social do que nos casos de sujeito identificados como psicopatas. Já nos psicopatas (TG), as alterações ocorrem de forma mais extensa e comprometem a personalidade global. Desse modo, supõe-se que o transtorno global de personalidade 
está relacionado com o conceito de psicopatia operacionalizado através da escala PCL-R, embora não possa ser reduzida a este (MORANA, 2003).

A realização do estudo acima se deu da seguinte maneira: inicialmente foi realizada a tradução da escala para o português; em seguida os casos diagnosticados como transtornos globais, de acordo com outros instrumentos utilizados anteriormente na pesquisa, preencheram os parâmetros para psicopatia na escala PCL-R (MORANA, 2003). Após o estabelecimento da correlação entre psicopatia e transtorno global, o passo seguinte da pesquisadora foi o de investigar as diferenças entre este grupo e o de transtornos parciais da personalidade, utilizando a PCL-R. Determinada a correlação entre ambos os construtos, foi possível a identificação do ponto de corte para a escala PCL-R na população forense brasileira (MORANA, 2003).

Como um dos resultados de comparação entre os grupos TG e TP, foi encontrado que no grupo TG predominou a ocorrência de crimes, incluindo estupro e homicídio. Verificou-se ainda que a frequência de crime por estupro e homicídio totalizou a maioria dos crimes praticados pelos grupos TG e TP, $84,9 \%$ e $87,0 \%$, respectivamente. Por fim, a faixa de pontuação de corte estabelecida a partir do estudo foi: não criminoso, 0 a 11,88, transtorno parcial, 11,9 a 22,7, transtorno global, 22,8 a 40 (MORANA, 2003).

O HCR-20, por outro lado, é um instrumento para avaliar o risco de violência, sendo apontado por Abdalla-Filho (2004) como um dos mais conhecidos pelos psiquiatras, junto ao PCL-R, o qual na época da publicação mencionada se encontrava em fase de validação para o Brasil. Um estudo de Telles et al. (2009) demonstrou ótimos resultados de confiabilidade em aplicação com uma população de pacientes de um instituto psiquiátrico forense, sendo pertinente ressaltar que Abdalla-Filho (2004) alerta sobre adotar uma postura equilibrada de não supervalorizar, mas também não desconsiderar as relações existentes entre o comportamento violento e alguns transtornos psiquiátricos. Composta por 20 itens, a escala é dividida em outras três subescalas: Historical (H), Clinical (C), Risk management (R; HCR-20). Ela avalia de forma multifatorial o risco de violência, inclusive para prevenir agressões futuras, abarcando fatores estáticos (H) e dinâmicos (C e R; TELLES et al., 2009).

Os 10 itens da subescala $\mathrm{H}$ tratam do histórico prévio da vida do examinando, como atos violentos, grave doença mental, abuso de 
substâncias e dificuldades precoces de adaptação. A subescala C é composta por 5 itens que abordam itens clínicos, no exemplo de falta de capacidade para insight, impulsividade, atitudes negativas. A terceira (subescala $\mathrm{R}$ ) investiga o gerenciamento de risco, como falta de suporte social e exposição a desestabilizadores. Cada item é avaliado numa pontuação de 0 a 2, de modo que o score varia entre 0 e 40. Entretanto, os autores do instrumento sugerem que o perito avalie em cima dos níveis de risco baixo (ou ausente), moderado ou alto, sendo mais importante voltar a atenção para os fatores de risco estudados e não aos pontos de corte, pois estes poderiam cair na rigidez de uma avaliação desprovida de sentido por trás daquele valor expressado (ABDALLA-FILHO, 2004).

Em relação ao Guia de Avaliação de Risco (VRAG), pode-se dizer que foi a primeira ferramenta desenvolvida para avaliar o risco de violência, em 1993. O qual é utilizado, principalmente, para predizer comportamentos violentos em indivíduos com transtorno mental grave ou histórico criminal longo (COSTA et al., 2015). Ele consiste em 12 itens, os quais são totalizados para se chegar a um escore geral do risco de violência. Segundo Hüss (2011), estudos indicam que o instrumento avalia de forma precisa em torno de 70 a $75 \%$ dos criminosos.

Neste sentido, um estudo foi desenvolvido por Amorim-Gaudêncio et al. (2015) para adaptação transcultural desse instrumento ao contexto brasileiro. Segundo os autores, as etapas do processo de adaptação transcultural aconteceram da seguinte forma: na primeira etapa, o instrumento original foi traduzido do inglês para o português por três tradutores fluentes no idioma. Na segunda etapa, em reunião, estas traduções foram sintetizadas. Na terceira etapa, o instrumento sintetizado foi encaminhado a outro tradutor fluente na língua inglesa para que ocorresse uma retradução. Na data de publicação do mencionado estudo, Amorim-Gaudêncio et al. (2015) explicaram que o instrumento não havia passado ainda por todas as etapas que um instrumento necessita para ser validado, no entanto estava no processo final de validação semântica. De acordo com Costa et al. (2015), a tradução da versão inglesa estava sendo utilizada para um estudo piloto de validação com apenados da Penitenciária de Segurança Média Juiz Hitler Cantalice.

Outra escala de autopreenchimento é a Barrat Impulsiveness Scale (BIS-11) que é composta por 30 itens relacionados às manifestações da 
impulsividade, tendo como base o modelo teórico proposto por Ernst Barratt. Nela, o avaliando deve analisar cada um dos itens considerando seu próprio comportamento e classificá-los a partir de uma escala Likert de quatro pontos, sendo 1, raramente ou nunca, e 4, quase sempre/sempre. A pontuação da escala varia de 30 a 120 pontos, e altos escores caracterizam a presença de comportamentos impulsivos. No modelo proposto por Ernst Barratt, a impulsividade é descrita como apresentando três componentes distintos, os quais são: o motor, no qual a impulsividade motora está relacionada a não inibição de respostas incoerentes com o contexto; a atencional, relacionada à impulsividade para tomada de decisão rápida; e a falta de planejamento, que engloba comportamentos orientados para o presente (MALLOY-DINIZ et al., 2010).

O estudo realizado por Malloy-Diniz et al. (2010) objetivou descrever o processo de tradução e adaptação da BIS-11 para o português no contexto brasileiro. A execução foi dividida em cinco etapas e todos os participantes consentiram em disponibilizar os dados obtidos. Esse trabalho resultou em uma adaptação brasileira do instrumento para avaliação da impulsividade, porém, de acordo com os autores mencionados, faz-se necessária a realização de mais investigações. Dentre estas, são exemplos as validades de critério e de construto, ou seja, se o mesmo cumpre com o objetivo de medir àquilo para o qual foi desenvolvido; se a estrutura fatorial da escala adaptada - quantos fatores são responsáveis por esse comportamento (HUTZ; BANDEIRA; TRENTINI, 2015) -, serve para avaliar o desempenho de um grupo mais heterogêneo de brasileiros nas diferentes regiões do país. Em termos da avaliação de risco, um estudo realizado por Baltieri e Boer (2015), com molestadores de crianças, indicou que altos escores no BIS-11 podem sinalizar um maior risco de reincidência a esse crime.

Os instrumentos apontados são demonstrações das possibilidades futuras no que se trata da validação e adaptação para o contexto brasileiro, a exemplo dos dois testes mencionados com parecer favorável no SATEPSI. Por essa razão, mesmo através de estudos mais específicos como os mencionados acima, instrumentos ainda não aptos à comercialização e aplicação à população geral e específicas por profissionais têm sua importância para ilustrar os resultados e perspectivas de um trabalho mais especializado no processo de avaliação de risco dos indivíduos aqui em 
foco. Apesar disso, entende-se que é extremamente limitante a ausência de mais pesquisas com instrumentos validados e métodos padronizados, pois dificulta bastante a atuação do psicólogo no contexto da avaliação psicológica forense e a credibilidade de sua prática.

\section{Considerações Finais}

O objetivo do presente artigo foi averiguar a literatura científica sobre as condições metodológicas da avaliação psicológica no contexto nacional com foco especial nos agressores sexuais, a partir da ótica da Psicologia Forense. Os achados, à raiz da análise documental, demonstraram uma escassez de pesquisas acerca do tema e carência de instrumentos e protocolos de avaliação específicos para esse grupo de agressores. Os resultados obtidos não permitem a comparação com os achados no contexto internacional devido à divergência metodológica, principalmente considerando que na maioria das avaliações (em pesquisas ou na clínica forense) a entrevista é a principal técnica utilizada e raramente há uma forma padronizada para esse método.

Nos estudos brasileiros, a instrumentalização é, em sua maioria, inespecífica (não desenvolvida para o objeto de avaliação) e subjetiva (com grande margem de viés do avaliador). Esse fato destoa sobremaneira dos estudos realizados no contexto internacional e impossibilita a prática psicológica com base na evidência científica defendida na contemporaneidade.

Portanto, se a pesquisa é considerada o motor da ciência, no quesito da avaliação clínica forense, a Psicologia brasileira precisa reconhecer suas limitações e tratar de fundamentar suas práticas a partir de uma avaliação psicológica de qualidade - válida e confiável. Para tal, é imperativo o desenvolvimento de testagem psicológica específica para os diferentes contextos e problemas legais. Enquanto isso não for levado a sério, a participação do psicólogo forense será sempre relativa, já que precisa demonstrar sua validade e efetividade.

O psicólogo forense tem suporte legal para sua atuação, como especificado na Lei de Execução Penal, Código Penal e Código Processual Penal brasileiros. Apesar disso, o Sistema Judiciário não explora tanto quanto poderia a atuação desse profissional, normalmente restringindo-a 
à avaliação de risco ou ao exame criminológico que, apesar de serem extremamente importantes, são apenas duas das muitas possibilidades da interseção entre Psicologia e Direito. E mesmo essas atuações precisam de suporte metodológico mais acurado.

Nesse sentido, voltamos ao ponto anterior, sendo necessário acompanhar o cenário internacional e não utilizarmos exclusivamente as avaliações clínicas (fundamentadas no conhecimento do perito e focada em sintomas), mas protocolos combinados de avaliações estruturadas e/ou atuariais com uso de escalas específicas e com a identificação de fatores de risco concretos para cada população. Portanto, deve-se somar a necessidade do desenvolvimento metodológico à qualificação profissional do psicólogo forense. Sem esses conjuntos de variáveis é praticamente impossível alcançar uma prática profissional de excelência.

Entende-se, por fim, que o tema "agressores sexuais" é extremamente relevante no contexto mundial e brasileiro, tendo em vista a realidade conjuntural e global identificada nos crimes contra diferentes tipos de vítimas, principalmente vítimas crianças e do sexo feminino. Considerando isso, questiona-se sobre quais os fatores envolvidos em uma agressão sexual fazem parte dos assuntos estudados pela Psicologia? Será que comportamentos disruptivos (que fogem à norma) podem ser melhor classificados/descritos? Como as emoções descrevem e guiam as ações perpetradas pelos agressores sexuais? Suas crenças e pensamentos têm um padrão que possa ser posto à prova no meio jurídico? Todas essas indagações fazem parte do âmago do escopo teórico do psicólogo forense e poderão ser melhor exploradas quando a ponte entre a Psicologia e o Direito for devidamente consolidada no nosso contexto; quando o psicólogo forense estiver tão presente quanto possível em locais onde a Justiça está: tribunais (de júri ou não), diligências, interrogatórios.

\section{REFERÊNCIAS}

ABDALLA-FILHO, Elias. Avaliação de risco em Psiquiatria Forense. Archives of Clinical Psychiatry, São Paulo, n. 31, v. 6, p. 279-284, 2004. https://doi.org/10.1590/ s0101-60832004000600002

ALMEIDA, Nemésio Vieira de Almeida. A entrevista psicológica como um processo dinâmico e criativo. Psic, São Paulo, v. 5, n. 1, p. 34-39, jun. 2004. 
AMORIM-GAUDÊNCIO, Carmen et al. Análise preliminar da versão portuguesa da guia de avaliação de risco da violência - VRAG. In: CONGRESSO INTERNACIONAL DE PSICOLOGIA JURÍDICA, 1., 2015, João Pessoa. Anais... João Pessoa: Editora da UFPB, 2015. p. 206-207. Disponível em: <http://www.abpj.org.br/ downloads/cedc555dd5dfd722eee2eee5e18f81b1.pdf $>$.

AZEVÊDO, Adriano Valério dos Santos. Construção do protocolo de avaliação psicológica hospitalar para a criança queimada. Avaliação Psicológica, v. 9, n. 1, p. 99-109, 2010.

BALTIERI, Danilo Antônio; BOER, Douglas Peter. Two clusters of child molesters based on impulsiveness. Brazilian Journal of Psychiatry, v. 37, n. 2, p. 139-145, 2015. https://doi.org/10.1590/1516-4446-2014-1568

BORSA, Juliane Callegaro. Considerações sobre o uso do Teste da Casa-Árvore -Pessoa - HTP. Avaliação Psicológica, v. 9, n. 1, p. 151-154, 2010.

BRASIL. Decreto-Lei no 2.848, de 7 de dezembro de 1940. Código Penal. Diário Oficial [da] República Federativa do Brasil, 7 dez. 1940. Disponível em: <http:// www.planalto.gov.br/ccivil_03/decreto-lei/Del2848compilado.htm>. Acesso em: 1 dez. 2019.

BRASIL. Código de Processo Penal. Decreto-Lei no 3.689, de 3 de outubro de 1941. Disponível em: <http://www.planalto.gov.br/ccivil_03/decreto-lei/del3689. htm>. Acesso em 1 dez. 2019.

BRASIL. Lei n. ${ }^{\circ} 4.119$, de 27 de agosto de 1962. Dispõe sobre os cursos de formação em psicologia e regulamenta a profissão de psicólogo. Diário Oficial da União, Poder Executivo, Brasília, DF, 27 ago. 1962. Disponível em: <http://www. planalto.gov.br/ccivil_03/leis/1950-1969/14119.htm>. Acesso em: 7 dez. 2019.

BRASIL. Lei n. ${ }^{\circ}$ 7.210, de 11 de julho de 1984. Institui a Lei de Execução Penal. Diário Oficial da União, Poder Executivo, Brasília, DF, 13 jul. 1984. Disponível em: http://www.planalto.gov.br/ccivil_03/leis/17210.htm. Acesso em: 1 dez. 2019.

BRASIL. Lei 10.792, de 2003 de 1 de dezembro de 2003. Altera a Lei $\mathrm{n}^{\circ} 7.210$, de 11 de junho de 1984 - Lei de Execução Penal e o Decreto-Lei no 3.689, de 3 de outubro de 1941 - Código de Processo Penal e dá outras providências.

BRASIL. Lei $n^{\circ}$ 12.015, de 07 de agosto de 2009. Altera o Título VI da Parte Especial do Decreto-Lei ${ }^{\circ} 2.848$, de 7 de dezembro de 1940 - Código Penal, e o art. $1^{\circ}$ da Lei no 8.072, de 25 de julho de 1990, que dispõe sobre os crimes hediondos, nos termos do inciso XLIII do art. $5^{\circ}$ da Constituição Federal e revoga a Lei ${ }^{\circ} 2.252$, de $1^{\circ}$ de julho de 1954 , que trata de corrupção de menores, Diário Oficial da União, 
Poder Executivo, Brasília, DF, 07 ago. 2009a. Disponível em: <www.planalto.gov. br/ccivil_03/_ato2007-2010/2009/lei/112015.htm>. Acesso em: 24 fev. 2020.

BRASIL. Supremo Tribunal Federal. Súmula Vinculante $n^{\circ} 26$. Para efeito de progressão de regime no cumprimento de pena por crime hediondo, ou equiparado, o juízo da execução observará a inconstitucionalidade do art. $2^{\circ}$ da Lei 8.072, de 25 de julho de 1990, sem prejuízo de avaliar se o condenado preenche, ou não, os requisitos objetivos e subjetivos do benefício, podendo determinar, para tal fim, de modo fundamentado, a realização de exame criminológico. Brasília, DF. Diário da Justiça Eletrônico, 23 dez. 2009b. Disponível em: https://www.stf. jus.br/arquivo/djEletronico/DJE_20091222_238.pdf. Acesso em: 24 fev. 2020.

BRASIL. Supremo Tribunal de Justiça. Súmula $n^{\circ} 439$. Admite-se o exame criminológico pelas peculiaridades do caso, desde que em decisão motivada. Brasília, DF. Diário da Justiça Eletrônico, 13 mai. 2010. Disponível em: https://scon.stj. jus.br/SCON/sumanot/toc.jsp?livre=(sumula\%20adj1\%20\%27439\%27).sub.\#TIT1TEMA0. Acesso em: 24 fev. 2020.

BUCK, John N. HTP Manual e Guia de Interpretação. São Paulo: Vetor, 2013.

BUSTAMANTE, Maria Inês et al. Validade por Estrutura Interna da Escala para Avaliação de Tendência à Agressividade. Psicol. cienc. prof., Brasília, v. 36, n. 3, p. 726-737, 2016. https://doi.org/10.1590/1982-3703001692016

CASARIN, Juliane Magda; BOTELHO, Elizabeth Hertel Lenhardt; RIBEIRO, Rosangela Kátia Sanches Mazzorana. Ofensores sexuais avaliados pelo Desenho da Figura Humana. Avaliação Psicológica, n. 15, v. 1, p. 61-72, 2016. https://doi. org/10.15689/ap.2016.1501.07

CAPEZ, Fernando. Curso de Processo Penal. 26. ed. São Paulo: Saraiva Educação, 2019.

CONSELHO FEDERAL DE PSICOLOGIA. Resolução nº 017, de 16 de Junho de 2012. Dispõe sobre a atuação do psicólogo como Perito nos diversos contextos. Brasília, DF, 2012. Disponível em: <https://site.cfp.org.br/wp-content/uploads/2013/01/ Resolu\%C3\%A7\%C3\%A3o-CFP-n\%C2\%BA-017-122.pdf>. Acesso em: 24 fev. 2020.

CONSELHO FEDERAL DE PSICOLOGIA. Resolução n ${ }^{\circ}$ 9, de 25 de Abril de 2018. Estabelece diretrizes para a realização de Avaliação Psicológica no exercício profissional da psicóloga e do psicólogo, regulamenta o Sistema de Avaliação de Testes Psicológicos - SATEPSI. Brasília, DF, 2018. Disponível em: <http://satepsi.cfp.org. br/docs/Resolução-CFP-nº-09-2018-com-anexo.pdf>. Acesso em: 24 fev. 2020. 
CONSELHO FEDERAL DE PSICOLOGIA. Resolução nº 06, de 29 de Março de 2019. Institui regras para a elaboração de documentos escritos produzidos pela(o) psicóloga(o) no exercício profissional. Brasília, DF, 2019. Disponível em: <https:// atosoficiais.com.br/cfp/resolucao-do-exercicio-profissional-n-6-2019institui-regras-para-a-elaboracao-de-documentos-escritos-produzidos-pela-opsicologa-o-no-exercicio-profissional-e-revoga-a-resolucao-cfp-no-15-1996-aresolucao-cfp-no-07-2003-e-a-resolucao-cfp-no-04-2019?q=006/2019>. Acesso em: 24 fev. 2020.

COSTA, Alexandre Pinheiro et al. Valoração da reincidência criminal mediante o guia de avaliação de risco da violência em amostras carcerárias. In: Encontro de Extensão, 16., 2015, João Pessoa. Anais... João Pessoa: Editora da UFPB, 2015.

DIAS, Luiza Graziela Santos; ROCHA, Adriana Cristina. Psicologia Forense: Uma Análise Teórica da Avaliação de Risco de Reincidência com Agressores Sexuais. Revista UNINGÁ, v. 50, n. 1, p. 77-81, 2016.

EMERY, Robert; LAUMANN-BILLINGS, Lisa. An overview of the nature, causes and consequences of abusive family relationships - Toward differentiating maltreatment and violence. American Psychologist, v. 53, n. 2, p. 121-135, 1998.

FERES, Carlos Roberto et al. Criminologia: Avaliação Psicológica de Grupos de Criminosos do Sistema Penitenciário do Estado de São Paulo. Revista USP, v. 53, p. 153-164, 2002. https://doi.org/10.11606/issn.2316-9036.v0i53p153-164

FORMIGA, Nilton Soares; MELLO, Ivana. Testes psicológicos e técnicas projetivas: uma integração para um desenvolvimento da interação interpretativa indivíduo -psicólogo. Psicol. cienc. prof., Brasília, v. 20, n. 2, p. 12-19, 2000.

FRAGA, Jéssica Buthers Lima Ferraz. As Contribuições da Entrevista Inicial para o Processo de Psicodiagnóstico. Pretextos - Revista da Graduação em Psicologia da PUC Minas, v. 1, n. 1, p. 61-85, 2016.

FONSECA, Antônio Castro. Psicologia Forense: uma breve introdução. 6. ed. Coimbra: Almedina, 2006. FÓRUM BRASILEIRO DE SEGURANÇA PÚBLICA FBSP. Anuário Brasileiro de Segurança Pública. 13.ed. 2019. Disponível em: <www. forumseguranca.org.br/atividades/anuario/>. Acesso em: 06 dez. 2019.

GONÇALVES, Gabriela do Nascimento et al. Um estudo psicanalítico do perfil psicológico de acusados sob delito de abuso sexual infantil. Rev. Conexão Eletrônica, v. 13, n.1, 2016.

HABIGZANG, Luísa et al. Abuso sexual infantil e dinâmica familiar: aspectos observados em processos jurídicos. Psicologia: Teoria e Pesquisa, v. 21, n. 3, p. 341-348, 2005. https://doi.org/10.1590/s0102-37722005000300011 
HERMOSO, Rocío Gomes. Informe sobre la eficacia de las predicciones sobre peligrosidad de los informes psicológicos forenses emitidos en los juzgados de vigilancia penitenciaria de Madrid. (Informe). On-line Infocope. Disponível em: <http://www.infocoponline.es/pdf/INFORMEFORENSES.pdf>. Acesso em: 06 dez. 2019.

HISATUGO, Carla Luciano Codani; CUSTÓDIO, Eda Marconi. Avaliação psicológica e da personalidade e o estudo normativo do Rorschach para o uso em crianças brasileiras. Psicólogo inFormação, v. 17, n. 17, p. 79-86, 2013.

HUSS, Matthew. Psicologia Forense: Pesquisa, Prática Clínica e Aplicações. Porto Alegre: Artmed, 2011.

HUTZ, Claudio Simon; BANDEIRA, Denise Ruschel. Desenho da figura humana. In CUNHA, J. A. (Org.). Psicodiagnóstico-V. Porto Alegre: Artmed, p. 507-512, 2007.

HUTZ, Claudio Simon; BANDEIRA, Denise Ruschel.; TRENTINI, Clarissa Marceli. Psicometria. 1. ed. Porto Alegre: Artmed, 2015.

INOUE, Silvia Regina Viodres; RISTUM, Marilena. Violência sexual: caracterização e análise de casos revelados na escola. Estud. psicol. (Campinas), Campinas, v. 25, n. 1, p. 11-21, 2008.

JOZEF, Flávio; SILVA, Jorge Adelino Rodrigues da. Psiquiatria Forense no Brasil: modelo de entrevista semi-estruturada para emprego em pesquisa psiquiátricoforense, com utilização do Hare PCL-R. J. bras. psiquiat, v. 51, n. 1, p. 47-54, 2002.

JUNG, Flávia Hermann. Avaliação Psicológica Pericial: Áreas e Instrumentos. Revista Especialize On-line IPOG, v. 1, n. 8, 2014. Disponível em https://www. ipog.edu.br/download-arquivo-site.sp?arquivo=a-entrevista-em-avaliacao-psicologica-7212133.pdf. Acesso em 05 set. 2019.

KARAM, Maria Lucia. Psicologia e sistema prisional. Rev. Epos, Rio de Janeiro, v. 2, n. 2, dez. 2011.

KHALED JR., Salah H. A produção analógica da verdade no processo penal. Revista Brasileira de Direito Processual Penal, Porto Alegre, vol. 1, n. 1, p. 166-184, 2015. http://dx.doi.org/10.22197/rbdpp.v1i1.9

LOPES JR., Aury. Direito Processual Penal. 16. ed. São Paulo: Saraiva Educação, 2019.

MALLOY-DINIZ, Leandro Fernandes et al. Tradução e adaptação cultural da Barratt Impulsiveness Scale (BIS-11) para aplicação em adultos brasileiros. J. bras. psiquiatr., Rio de Janeiro, v. 59, n. 2, p. 99-105, 2010. http://dx.doi.org/10.1590/ S0047-20852010000200004 
MARIN, Matheus Cheibub David; BALTIERI, Danilo Antonio. Crimes sexuais e suas particularidades na avaliação de risco e no cumprimento da medida de segurança. IN: CORDEIRO, Quirino; LIMA, Mauro Gomes Aranha de. (Orgs.), Medida de Segurança: Uma questão de saúde e ética [Online]. São Paulo: Conselho Regional de Medicina, 2013, p. 157-178. Disponível em: <http://saudedireito.org/wp-content/uploads/2013/11/Livromedidaseguranca.pdf>. Acesso em: 01 dez. 2019.

MENESES, Fernanda Figueiredo Falcomer et al. Intervenção psicossocial com o adulto autor de violência sexual intrafamiliar contra crianças e adolescentes. Contextos Clínic, São Leopoldo, v. 9, n. 1, p. 98-108, jun. 2016. http://dx.doi. org/10.4013/ctc.2016.91.08

MESSA, Alcione Aparecida. Psicologia Jurídica. São Paulo: Atlas, 2010.

MORANA, Hilda Clotilde Penteado. Identificação do ponto de corte para a escala PCL-R (Psychopathy Checklist Revised) em população forense brasileira: caracterização de dois subtipos de personalidade; transtorno global e parcial. 2003. Tese (Doutorado em Psiquiatria) - Faculdade de Medicina, Universidade de São Paulo, São Paulo, 2004. doi:10.11606/T.5.2004.tde-14022004-211709.

MOURA, Andreína da Silva; KOLLER, Sílvia Helena. A criança na visão de homens acusados de abuso sexual: um estudo sobre distorções cognitivas. Psico-USF, v. 13, n. 1, p.85-94, 2008.

MOURA, Andreína da Silva; KOLLER, Sílvia Helena. Expressões de empatia em homens acusados de abuso sexual infantil. Psico, v. 41, n. 2, p. 184-191. 2010.

NASCIMENTO, Regina Sonia Gattas F. do. Estudo normativo do sistema compreensivo do Rorschach para a cidade de São Paulo. Psico-USF (Impr.), Itatiba, v. 7, n. 2, p. 127-141, dez. 2002.

NETTO, Cláudio Saad. Prova pericial e prova documental em face da lei das interceptações telefônicas. RIDB, v. 3, n. 8, p.6095-6112, 2014.

NEVES, Ana Cristina. Avaliação de risco de reincidência criminal: Aplicações e implicações em Psicologia Forense. In: OLHARES DA PSICOLOGIA, 2014, Almada. Comunicação... Almada: Monte de Caparica, 2014.

NORONHA, Ana Paula Porto. Análise de testes de personalidade: qualidade do material, das instruções, da documentação e dos itens qualidade de testes de personalidade. Estud. psicol. (Campinas), Campinas, v. 19, n. 3, p. 55-65, 2002.

PECHORRO, Pedro Santos; POIARES, Carlos; VIEIRA, Rui Xavier. Caracterização psicológica de uma amostra forense de abusadores sexuais. Análise Psicológica, Portugal, v. 26, n. 4, p. 615-623, 2008. 
PENIDO, Flávia Ávila; GONÇALVES, Jordânia Cláudia de Oliveira. O exame criminológico como mecanismo de biopolítica. Revista de Criminologias e Políticas Criminais, v. 1, n. 2, p. 40-56, 2015. https://doi.org/10.26668/IndexLawJournals/2526-0065/2015.v1i1.33

PERVIN, Lawrence A.; JOHN, Oliver P. Personalidade: teoria e pesquisa [Online]. Artmed Editora, 2004. Disponível em: <https://books.google.com.br/books?hl=p-

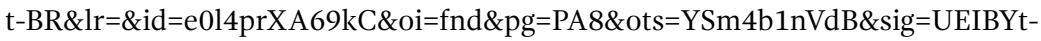
njQ0V4VmLmD1UUrIdOiqo\&redir_esc $=\mathrm{y} \# \mathrm{v}=$ onepage $\& \mathrm{q} \& \mathrm{f}=$ false $>$. Acesso em: 01 dez. 2019.

PIMENTEL, Adelma. Avaliação psicológica na DEAM: um estudo de caso de violência sexual infantil. Rev. Mal-Estar Subj., Fortaleza, v. 10, n. 2, p. 585-603, 2010.

PITHERS, William D. Empathy: Definition, enhancement and relevance to the treatment of sexual abusers. Journal of Interpersonal Violence, v.4, n.3, p. 257-284, 1999. https://doi.org/10.1177/088626099014003004

REIS, Daniela Castro dos. Autores de Agressão Sexual de Crianças e Adolescentes: Características Biopsicossociais e Trajetórias de Vida. 2016. Tese (Doutorado em Teoria e Pesquisa do Comportamento) - Núcleo de Teoria e Pesquisa do Comportamento, Universidade Federal do Pará, Belém.

REISHOFFER, Jefferson Cruz; BICALHO, Pedro Paulo Gastalho. Exame criminológico e psicologia: crise e manutenção da disciplina carcerária. Fractal: Revista de Psicologia, v. 29, n. 1, p. 34-44, 2017. https://doi.org/10.22409/1984-0292/ v29i1/1430

RIGONATTI, Sérgio Paulo et al. Personality disorders in rapists and murderers from a maximum security prison in Brazil. Int J Law Psychiatry, v. 29, n.5, p.361-369, 2006.

RISTUM, Marilena; BASTOS, Ana Cecília de Sousa. Violência urbana: uma análise dos conceitos de professores do ensino fundamental. Ciência e Saúde Coletiva, v. 9, n. 1, p. 225-239, 2004.

ROTHER, Edna Terezinha. Revisão sistemática X revisão narrativa. Acta paul. enferm., São Paulo, v. 20, n. 2, p. v-vi, 2007.

ROVINSKI, Sônia Liane Reichert. Fundamentos da Perícia Psicológica Forense. 3. ed. São Paulo: Vetor, 2013. https://doi.org/10.1016/j.ijlp.2006.01.003

SALMEIRÃO, Cristiano. Do procedimento probatório e do momento da sua produção com participação ativa do magistrado em busca da decisão justa no direito processual pena. Revista Âmbito Jurídico, São Paulo, n. 98, 2012. Disponível em: 
<https://ambitojuridico.com.br/edicoes/revista-98/do-procedimento-probatorio -e-do-momento-da-sua-producao-com-participacao-ativa-do-magistrado-em-buscada-decisao-justa-no-direito-processual-penal/\#_ftn16>. Acesso em: 27 fev. 2020.

SANTOS, Rodrigo Soares; ANDRETTA, Michelli Miranda; COUTO, Gleiber. Avaliação Psicológica Forense e Ética Profissional. PsicoFAE, Curitiba, v. 1, n. 1, p. 45-59, 2012.

SCORTEGAGNA, Silvana Alba; AMPARO, Deise Matos do. Avaliação psicológica de ofensores sexuais com o método de Rorschach. Aval. Psicol., Itatiba, v.12, n.3, p.411-419, 2013.

SERAFIM, Antonio de Pádua; SAFFI, Fabiana. Psicologia e práticas forenses. Barueri: Manole, 2014.

SILVA, Roselaine B. Ferreira da. et al. O Desenho da figura humana e seu uso na Avaliação Psicológica. Psicol. Argum., v.28, n.60, p.55-64. 2010.

SILVA, Veronica R. da Costa. Falsas acusações de abuso sexual contra a infância: Deficiências do sistema penal em face da fragilidade da prova. Monografia (Faculdade de Direito) - Universidade Federal do Rio Grande do Sul, Porto Alegre, 2013.

SISTO, Fermino Fernandes; CECILIO-FERNANDES, Dario; SILVEIRA, Fernando José. Funcionamento diferencial de condutas agressivas em jovens infratores e universitários agressivos. Estud. pesqui. psicol., Rio de Janeiro, v. 12, n. 1, p. 158174, abr. 2012.

SISTO, Fermino Fernandes et al. Estudo preliminar para a construção de uma escala de agressividade para universitários. Aletheia, Canoas, n. 28, p. 77-90, dez. 2008.

SOUSA, Renata Floriano de. Cultura do estupro: prática e incitação à violência sexual contra mulheres. Estudos Feministas, v. 25, n. 1, p. 9-29, 2017.

TEIXEIRA-FILHO, Fernando Silva et al. Tipos e consequências da violência sexual sofrida por estudantes do interior paulista na infância e/ou adolescência. Psicol. Soc., Belo Horizonte, v. 25, n. 1, p. 90-102, 2013.

TELLES, Lisieux Elaine de Borba et al. . Reliability of the Brazilian version of HCR-20 Assessing Risk for Violence. Revista Brasileira de Psiquiatria, v. 31, n.3, p. 253-256, 2009. http://dx.doi.org/10.1590/S1516-44462009005000001

WEBSTER, Stephen D.; BEECH, Anthony R. The nature of sexual offenders' affective empathy: A grounded theory analysis. Sexual Abuse: A Journal of Research and Treatment, v.12, n.4, p. 249-261, 2000. https://doi.org/10.1177/107906320001200402 
WIELEWICKI, Annie. Publicações Científicas Brasileiras Sobre o Pedófilo e o Agressor Sexual Infantil. 2017. Dissertação (Mestrado em Análise do Comportamento) - Programa de Pós Graduação em Análise do Comportamento, Universidade Estadual de Londrina, Londrina.

WRUBEL, Regina. Avaliação psicológica no contexto prisional: a questão do exame criminológico. 2013. Monografia (Especialização em Saúde Mental e Intervenção Psicológica) - Universidade Estadual de Maringá.

ZÚQUETE, José Gonçalo Estrela; NORONHA, Ceci Vilar. Pedófilos e agressores sexuais de crianças e adolescentes: narrativas a partir do cárcere. IN: COELHO, Maria Thereza Ávila Dantas; CARVALHO FILHO, Milton Júlio de. (orgs). Prisões numa abordagem interdisciplinar [online]. Salvador: EDUFBA, 2012, p. 145-160. Disponível em <http://books.scielo.org/id/7mkg8/pdf/coelhos-9788523217358-10. pdf>. Acesso em 07. set. 2019.

\section{Informações adicionais e declarações dos autores (integridade científica)}

Agradecimentos (acknowledgement): Agradecemos ao Laboratório de Avaliação e Intervenção Clínica Forense pelo apoio logístico na realização do trabalho. Igualmente, agradecemos ao Departamento de Psicologia da UFPB pelo oferecimento da Disciplina Tópicos de Avaliação Psicológica com foco na Avaliação Forense, responsável pelo desenvolvimento do trabalho que originou esse artigo.

Declaração de conflito de interesses (conflict of interest declaration): os autores declaram que não existe conflitos de interesse na realização das pesquisas para redação do artigo e que as conclusões apresentadas são imparciais e independentes de seus interesses pessoais.

Declaração de autoria e especificação das contribuições (declaration of authorship): todas e somente as pessoas que atendem os requisitos de autoria deste artigo estão listadas como autores; todos os coautores se responsabilizam integralmente por este trabalho em sua totalidade. 
- Álice Lira-Cardoso: desenvolvimento da metodologia (methodology), coleta e análise de dados (data curation), levantamento bibliográfico (investigation), redação (writing - original draft), participação ativa nas discussões dos resultados (validation), revisão crítica com contribuições substanciais (writing - review and editing), aprovação da versão final.

- Gabriella Medeiros Silva: desenvolvimento da metodologia (methodology), revisão bibliográfica (investigation), redação (writing - original draft), participação ativa nas discussões dos resultados (validation), revisão crítica com contribuições substanciais (writing - review and editing), aprovação da versão final.

- Thiago Pinto Siqueira Campos: redação (writing - original draft), participação ativa nas discussões dos resultados (validation), revisão crítica com contribuições substanciais (writing - review and editing), aprovação da versão final.

- Lizandra Monteiro Ciraulo: redação (writing - original draft), participação ativa nas discussões dos resultados (validation), aprovação da versão final.

- Carmen Walentina Amorim Gaudêncio Bezerra: projeto e esboço inicial, desenvolvimento da metodologia (methodology), redação (writing - original draft), participação ativa nas discussões dos resultados (validation), revisão crítica com contribuições substanciais (writing - review and editing), aprovação da versão final.

Declaração de ineditismo e originalidade (declaration of originality): os autores asseguram que o texto aqui publicado não foi divulgado anteriormente em outro meio e que futura republicação somente se realizará com a indicação expressa da referência desta publicação original; também atestam que não há plágio de terceiros ou autoplágio. 
Dados do processo editorial

(http://www.ibraspp.com.br/revista/index.php/RBDPP/about/editorialPolicies)

- Recebido em: 07/01/2020

Equipe editorial envolvida

- Controle preliminar e verificação de plágio: 07/01/2020

- Avaliação 1: 29/01/2020

- Avaliação 2: 06/02/2020

- Editor-chefe: 1 (VGV)

- Editora-associada: 1 (MSG)

- Revisores: 2

- Decisão editorial preliminar: 15/02/2020

- Retorno rodada de correções 1: 29/02/2020

- Decisão editorial preliminar 2: 03/03/2020

- Retorno rodada de correções 2: 04/03/2020

- Decisão editorial final: 04/03/2020

\section{COMO CITAR ESTE ARTIGO:}

LIRA-CARDOSO, Álice; SILVA, Gabriella M.; SIQUEIRA-CAMPOS, Thiago P.; CIRAULO, Lizandra M.; AMORIM-GAUDÊNCIO, Carmen. Avaliação psicológica de agressores sexuais no contexto brasileiro: instrumentos e perspectivas. Revista Brasileira de Direito Processual Penal, Porto Alegre, vol. 6, n. 1, p. 247-281, jan./abr. 2020. https://doi.org/10.22197/rbdpp.v6i1.320

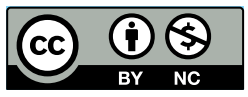

Esta obra está licenciada com uma Licença Creative Commons Atribuição-NãoComercial 4.0 Internacional. 